\title{
Tumor do estroma gastrintestinal (GIST): relato de caso
}

\section{Gastrintestinal stromal tumor (GIST): case report}

Isabel Irene Rama leal; ; Herbeth Franco Queiroz 2; Thiago Santos lima Almendra ${ }^{3}$; Andréia Reis Pereira ${ }^{3}$; ELSON Roberto RibeIRO-FARIA ${ }^{4}$

\section{INTRODUÇÃO}

$\mathrm{O}$ s tumores do estroma gastrintestinal (GISTs Gastrintestinal Stromal Tumors) são as lesões neoplásicas mesenquimatosas mais comuns do trato gastrintestinal ${ }^{1-3}$. Representam $1 \%$ de todos os tumores do tubo digestório ${ }^{2}$. Tais tumorações já foram confundidas com outros tipos de tumores, especialmente os leiomiomas e leiomiossarcomas. Com o avanço da imunohistoquímica e da microscopia eletrônica, pode-se separá-los em um grupo à parte, levando à introdução do termo GIST, em 1983 por Mazur e Clark ${ }^{3}$.

\section{RELATO DO CASO}

J.S., 46 anos, masculino, deu entrada no Pronto Socorro com relato de dor espasmódica abdominal há 20 dias, associada à dispnéia e edema de membros inferiores. Referia, ainda, inapetência, perda de $10 \mathrm{~kg}$ de peso, úlcera gástrica há dez anos, melena, anemia, fraqueza e necessidade de oito unidades de concentrado de hemácias.

Levado à laparotomia por síndrome da resposta inflamatória sistêmica e irritação peritonial, identificou-se pequena ascite, abscesso subfrênico, lesão lacerante no segmento 8 do fígado e tumoração de $10 \times 9 \times 5 \mathrm{~cm}(163 \mathrm{~g})$, apensa à serosa do jejuno. Realizou-se enterectomia com reconstrução término - terminal, curativo cirúrgico e foi programada a relaparotomia. O exame macroscópico do segmento ressecado evidenciou tumoração vegetante intraluminal $(5 \times 4 \times 3 \mathrm{~cm})$ contígua à lesão da serosa. Células fusiformes em feixes curtos, atipia nuclear moderada e mais de cinco figuras de mitose em 50 campos de grande aumento foram detectadas à microscopia (Figura 1). A imunohistoquímica revelou positividade para o CD117 (policlonal) (Figura 2). 0 paciente encontra-se vivo e sem evidências de recidiva tumoral após 9 meses de seguimento.

\section{DISCUSSÃO}

Embora constituam as neoplasias mesenquimatosas mais comuns do trato gastrintestinal, os GISTs são

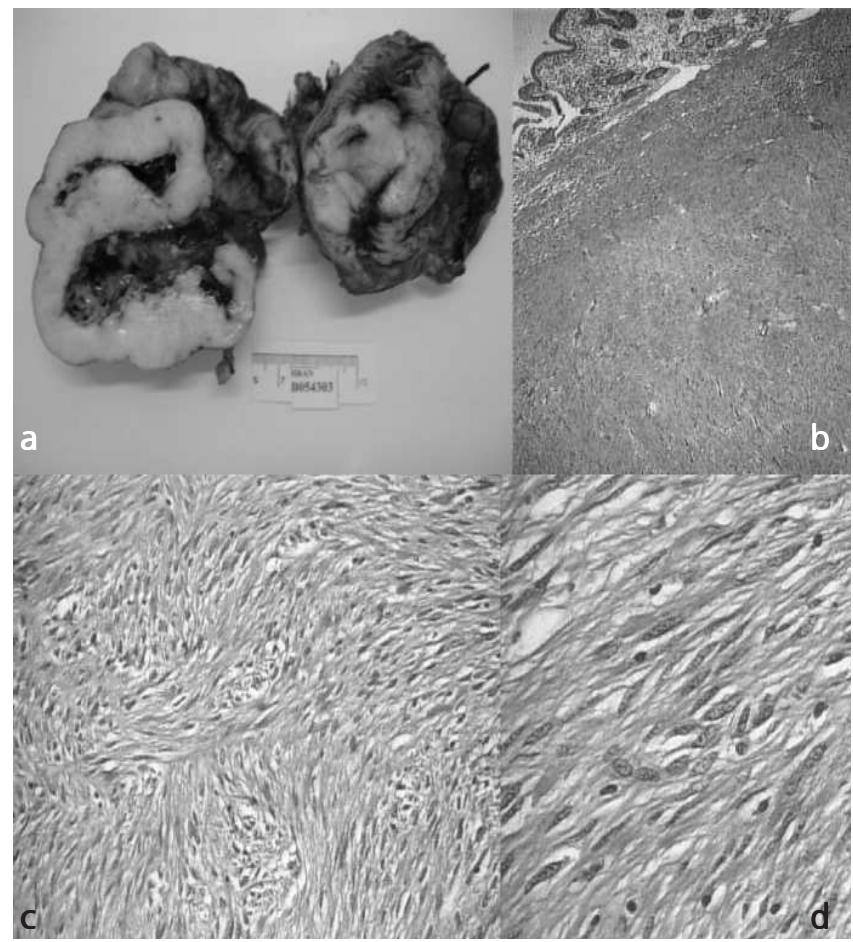

Figura 1 - a) tumoração em forma de ampulheta compreendendo segmentos, extra-intestinal medindo $10 \mathrm{~cm} e$ intra-intestinal medindo $5 \mathrm{~cm}$. É de coloração brancacenta e aspecto fasciculado. O segmento maior mostra extensa necrose com cavitação central; b) Corte histológico mostrando tumoração comprometendo a muscular da mucosa, muscular própria e serosa. (HE, 40X); c) Feixes curtos de células fusiformes com disposição em redemoinho. (HE, 200X); d) Células fusiformes com discreta a moderada atipia nuclear. (HE, 400X).

raros e ocupam a terceira posição na lista de todos os tipos de tumores da mesma região, perdendo em prevalência para os adenocarcinomas e os linfomas ${ }^{3}$.

Aproximadamente uma a duas pessoas em cada 100.000 é diagnosticada com GIST a cada ano nos EUA². Acometem igualmente o sexo masculino e feminino ${ }^{1-4}$. Apresentam-se com comportamento biológico de amplo espectro, desde tumores indolentes de baixo crescimento a neoplasias malignas agressivas com propensão para infil-

\footnotetext{
Trabalho realizado no Hospital Regional da Asa Norte do Distrito Federal Brasília- DF-BR.

1. Patologista do Hospital Universitário de Brasília- UNB- DF-BR; 2. Ex-Médico Residente da Clínica Cirúrgica do Hospital Regional da Asa Norte do Distrito Federal Brasília- DF-BR; 3. Acadêmicos de Medicina (internato) da Escola Superior de Ciências da Saúde da Fundação de Ensino e Pesquisa em Ciências da Saúde do Distrito Federal- DF-BR; 4. Docente de Clínica Cirúrgica da Escola Superior de Ciências da Saúde da Fundação de Ensino e Pesquisa em Ciências da Saúde do Distrito Federal- DF-BR.
} 


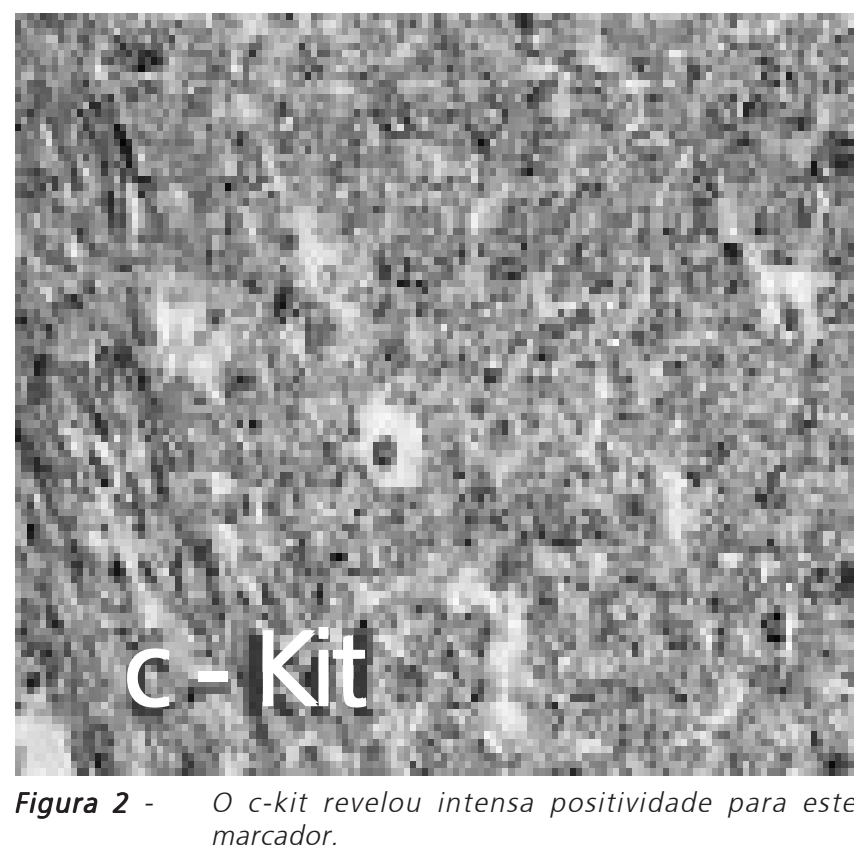

tração de órgãos adjacentes, metastatização para o fígado e recidiva abdominal ${ }^{2}$. De acordo com os estudos de Kindblom ${ }^{2,3}$, de 1998, a unidade progenitora dos GISTs é uma célula - tronco mesenquimatosa, pluripotencial e programada para a diferenciação em células intersticiais de Cajal ( células marca-passo da motilidade gastrintestinal). Do ponto de vista histopatológico, ocorrem mutações nas proteínas c-Kit proto - oncogene, transformando-a em
c-Kit ativado, passando a estimular a proliferação irregular e descontrolada das células e alterando os mecanismos de apoptose ${ }^{1-4}$.

Os GISTs podem acometer qualquer parte do trato gastrintestinal, porém tem como sítios mais comuns o estômago (50-70\%), o intestino delgado (20-30\%, estando $1 / 3$ no duodeno), seguidos de cólon e reto (5-15\%) e esôfago $(<5 \%)$ (2). Entretanto, podem acometer outras áreas como omento, mesentério, retroperitônio e vesícula biliar ${ }^{3}$.

O tamanho tumoral do presente caso foi determinante para a sua classificação em tumor de alta agressividade biológica, de acordo com o National Institute of Health (NIH).

A positividade para o CD117 e o CD34 em até $72 \%$ dos casos de GIST constitui o grande diferencial entre os tumores do estroma gastrintestinal e os Leiomiomas e os Leiomiossarcomas ${ }^{1-5}$.

A ressecção cirúrgica é o método de escolha em todos os casos de GIST5. Contudo, o resultado desta terapia dependerá do comportamento biológico do tumor (tamanho e número de mitoses) 2,3,5.

A terapêutica alternativa mais eficaz na atualidade é o STI-571 (Mesilato de Imatinibe- GLIVEC $($ Novartis), um inibidor seletivo da tirosina quinase expressa na proteína c-kit ${ }^{3}$. Tem sido utilizada com sucesso nos casos de tumores inoperáveis, ressecção cirúrgica incompleta ou metastáticos ${ }^{5}$. Em setembro de 2002, o Ministério da Saúde aprovou o protocolo clínico para tratamento do GIST no Brasil 5 .

\section{A B S T R A C T}

The authors report a case of a male patient in his forties with progressive abdominal pain associated with weight loss, dyspnea, and edema of the inferior limbs, culminating in a surgical acute abdomen. A segmental enterectomy containing a lesion of about $10 \mathrm{~cm}$ in diameter was performed. It was later confirmed, by means of immuno-hystochemistry, as being a Gastrointestinal Stromal Tumor of high biological aggressiveness. Etiology, diagnosis, classification, prognosis and therapeutic with Imatinib Mesylate - STI-571 (Glivec® - Novartis) are hence discussed.

Key words: Gastrointestinal Stromal Tumors. Gastrointestinal neoplasm. Stromal cell. Enzyme Inhibitors.

\section{REFERENCIAS}

1. Fletcher CD, Berman JJ, Corless C, Gorstein F, Lasota J, Longley BJ, Miettinen M, O'Leary TJ, Remotti H, Rubin BP, Shmookler B, Sobin LH, Weiss SW. Diagnosis of gastrointestinal stromal tumors: A consensus approach. Hum Pathol 2002; 33(5):459-65.

2. Machairas A, Karamitopoulou E, Tsapralis D, Karatzas T, Machairas N, Misiakos EP. Gastrointestinal stromal tumors (GISTs): an updated experience. Diag Surg 2010; 55(12):3315-27.

3. Krajinovic K, Germer CT, Agaimy A, Wünsch PH, Isbert C. Outcome after resection of one hundred gastrointestinal stromal tumors. Diag Surg 2010; 27(4):313-9.

4. Berman J, O'Leary TJ. Gastrointestinal stromal tumor workshop. Hum Pathol 2001; 32(6):578-82.

5. Tratamento do Tumor de Estroma Gastrointestinal (GIST) pelo SUS. Portaria n 1655, Brasília: Ministério da Saúde. Diário Oficial da União. 2002 Set 19: no 182 - seção 1.
Recebido em 20/12/2006

Aceito para publicação em 25/02/2007

Conflito de interesse: nenhum

Fonte de financiamento: nenhuma

\section{Como citar este artigo:}

Leal IIR, Queiroz HF, Almendra TSL, Pereira AR, Ribeiro-Faria ER. Tumor do estroma gastrointestinal (GIST): relato de caso. Rev Col Bras Cir. [periódico na Internet] 2011; 38(1). Disponível em URL: http:// www.scielo.br/rcbc

\section{Endereço para correspondência:}

Elson Roberto Ribeiro Faria

E-mail: urodinamicabsb@hotmail.com / e_faria@terra.com.br 